\title{
Obtenção e caracterização de materiais argilosos quimicamente ativados para utilização em catálise
}

\section{(Preparation and characterization of chemically activated clays for use in catalysis)}

\author{
M. G. F. Rodrigues ${ }^{1}$, K. R. O. Pereira', F. R. Valenzuela-Diaz ${ }^{2}$ \\ ${ }^{I}$ Departamento de Engenharia Química, Centro de Ciências e Tecnologia, Universidade Federal de Campina \\ Grande \\ Av. Aprígio Veloso, 882, Bodocongó, Campina Grande, PB 58109-970 \\ tel.: (83)3101115, fax: (83)3101114 \\ ${ }^{2}$ Laboratório de Matérias-Primas Particuladas e Sólidos Não Metálicos, Departamento de Engenharia \\ Metalúrgica e de Materiais, Escola Politécnica da Universidade de S. Paulo, \\ Ed. Semi-Industrial, R. do Lago 250, Cidade Universitária S. Paulo, SP 05508-900 \\ tel.:(11)3091-2279, fax:(11)30912275 \\ meiry@deq.ufcg.edu.br,frrvdiaz@usp.br,kleberson.pereira@poli.usp.br
}

\begin{abstract}
Resumo
O principal objetivo deste trabalho é caracterizar argilas esmectíticas "Chocolate" de Boa-Vista, PB, tanto na sua forma natural quanto tratada quimicamente, visando sua aplicação em catálise. As argilas foram caracterizadas por fluorescência de raios X, difração de raios X e espectrofotometria de absorção óptica na região do infravermelho. Os resultados mostraram que o tratamento ácido alterou a estrutura da montmorilonita. A reação de isomerização do metaxileno, para o material ativado, mostrou que a argila ácida foi mais ativa que a natural.
\end{abstract}

Palavras-chave: argilas esmectíticas, ativação ácida, reação de isomerização.

\begin{abstract}
The main objective of this paper is to characterize the chocolate smectite clays of Boa-Vista, PB, Brazil, in their natural form, and after chemical treatment, for their application in catalysis. The experimental methods were: $X$ ray fluorescence, X-ray diffraction and infrared spectroscopy. The results show that the acid treatment altered the montimorillonite structure. The obtained reaction (isomerization of m-xylene) for the treated material showed that treated clays were more active than the natural ones.
\end{abstract}

Keywords: smectitic clays, acid activation, isomerization reaction.

\section{INTRODUÇÃO}

As argilas naturais possuem uma baixa capacidade para reações catalíticas em meios polares ou não-polares. As propriedades estruturais destes materiais podem ser modificadas por métodos de ativação para produzir catalisadores com alta acidez, alta área específica, alta porosidade e termicamente estáveis [1].

A ativação ácida de minerais argilosos é um dos métodos propostos mais efetivos para produzir materiais ativos para adsorção e catálise. As argilas ativadas com ácido tem encontrado aplicações, em particular, nos processos industriais como a alquilação de fenóis [2], polimerização de hidrocarbonetos não saturados [3, 4], clarificação de óleos comestíveis [5] e produção de papel para cópias xérox [6].

As argilas ativadas têm atraído atenção como catalisadores para uma variedade de reações ácidas [7-9].

O comportamento físico-químico dos minerais argilosos tem sido estudado devido a sua relação com adsorvente e/ou propriedades catalíticas. Este comportamento é governado pela extensão e natureza da superfície externa, que pode ser modificada por tratamentos químicos e térmicos, os quais aumentam a atividade catalítica e adsorvente de minerais argilosos, mas tratamentos muito fortes diminuem esta atividade [10-14]. 
O tratamento ácido da montmorilonita tem a finalidade de aumentar a mesoporosidade contribuindo para um suporte catalítico efetivo. Assim, é importante compreender como se modificam as propriedades texturais, bem como as propriedades de superfície sob diferentes condições de ativação [15-18].

O objetivo deste trabalho é caracterizar uma argila bentonítica de Boa Vista (PB), ativada com $\mathrm{HCl}$, para fins catalíticos.

\section{MATERIAIS E MÉTODOS}

\section{Materiais}

Foi utilizada uma amostra de bentonita de cor chocolate, proveniente da jazida Primavera, Boa Vista, PB, fornecida, na forma de aglomerados pela Bentonit União Nordeste (BUN), empresa situada no distrito industrial da cidade de Campina Grande, PB.

\section{Ativação ácida}

A amostra foi moída em moinho vibratório de bola MLW modelo KM1 até passagem completa em peneira malha 80 (abertura $0,177 \mathrm{~mm}$ ). A amostra foi caracterizada na sua forma natural (seca e moída) e então submetida a ativação ácida. A ativação foi efetuada com ácido clorídrico nas seguintes condições: temperatura $90^{\circ} \mathrm{C}$; tempos de reação $=1 \mathrm{~h}, 2 \mathrm{~h}, 3 \mathrm{~h}$ e $7 \mathrm{~d}$; concentração do ácido $6 \mathrm{M}$; relação massa argila/volume solução $1 \mathrm{~g} / 10 \mathrm{~mL}$.

Inicialmente foi preparada a solução aquosa 6M (100 $\mathrm{mL}$ ) com o ácido clorídrico, a qual foi adicionada sobre a amostra $(10 \mathrm{~g})$ seca e moída, que estava contida em recipiente de vidro. Em seguida, a mistura foi agitada manualmente, tampou-se o recipiente com tampa de polipropileno e a dispersão foi levada a estufa, a $90{ }^{\circ} \mathrm{C}$ $\pm 5^{\circ} \mathrm{C}$. Após o tempo de reação $(1 \mathrm{~h}, 2 \mathrm{~h}, 3 \mathrm{~h}$ e $7 \mathrm{~d})$, as misturas obtidas foram filtradas a vácuo (funil de Büchner e Kitassato) e lavadas com água destilada até que o $\mathrm{pH}$ dos filtrados ficasse em torno de 7. Os materiais obtidos foram secos em estufa a $60^{\circ} \mathrm{C} \pm 5^{\circ} \mathrm{C}$ e após $48 \mathrm{~h}$ foram desagregados em almofariz manual e caracterizados.

\section{Técnicas de caracterização}

As amostras da argila, tanto a natural como as ativadas, foram submetidas a análise por fluorescência de raios X (Philips modelo PW2400) para determinar a sua composição química.

A análise por difração de raios $\mathrm{X}$ foi feita em difratômetro Siemens D5000, com radiação $\mathrm{K}_{\alpha}$ do cobre, $40 \mathrm{kV}-40 \mathrm{~mA}$, passo de $0,02 \mathrm{em} 2 \theta$ e tempo por passo de $1 \mathrm{~s}$.

As amostras foram prensadas em pastilhas de $\mathrm{KBr}$ e analisadas em comprimentos de onda na faixa de 4000 a $400 \mathrm{~cm}^{-1} \mathrm{em}$ espectrômetro FTIR Magna 560 ESPS Nicolet.
Estudo do uso da argila ativada com ácido clorídrico como catalisador

A isomerização do meta-xileno foi realizada num micro reator de leito fixo a $623 \mathrm{~K}$ sobre $200 \mathrm{mg}$ de catalisador, sob pressão atmosférica e fluxo de reagente $8 \mathrm{~mL} \cdot \mathrm{h}^{-1}$ e tempo de reação $30 \mathrm{~min}$. As amostras (argilas bentoníticas $80 \mathrm{mesh}$ : sem tratamento e ativadas: $1 \mathrm{~h}, 2 \mathrm{~h}$ e $3 \mathrm{~h}$ ) foram pré-tratadas sob um fluxo de nitrogênio de $3600 \mathrm{~mL} \cdot \mathrm{h}^{-1}$ por $2 \mathrm{~h}$.

Utilizou-se um cromatógrafo CG90 da Instrumentos Científicos CG Ltda, equipado com um detector de condutividade térmica (DCT).

\section{RESULTADOS E DISCUSSÃO}

\section{Análise química}

Os resultados de fluorescência de raios X são mostrados na Tabela I, que apresenta a composição química das amostras naturais e ativadas com ácido clorídrico. O tratamento removeu o cátion trocável $\left(\mathrm{Ca}^{2+}\right)$ e observou-se uma redução dos cátions que formam a parte da estrutura octaédrica, como alumínio, magnésio e ferro. A razão $\mathrm{SiO}_{2} / \mathrm{Al}_{2} \mathrm{O}_{3}$ aumentou com o tratamento ácido, indicando que existe um aumento de silício e, em contrapartida, uma extração de alumínio.

Tabela I - Análise química da argila bentonítica 80 mesh sem tratamento e após ativação com $\mathrm{HCl}(6 \mathrm{M})$ por $1 \mathrm{~h}, 2 \mathrm{~h}$ e $3 \mathrm{~h}$.

[Table I - Chemical analysis of the smectite clay 80 mesh: untreated smectite and smectite activated with $\mathrm{HCl}$.]

\begin{tabular}{|c|c|c|c|c|}
\hline \multirow[t]{2}{*}{ Compone } & \multicolumn{4}{|c|}{ te $\quad$ Argila bentonítica 80 mesh } \\
\hline & $\begin{array}{c}\text { Sem } \\
\text { tratamento }\end{array}$ & $1 \mathrm{~h}$ & $2 \mathrm{~h}$ & $3 \mathrm{~h}$ \\
\hline $\mathrm{SiO}_{2}$ & 56,92 & 57,17 & 57,11 & 57,20 \\
\hline $\mathrm{Al}_{2} \mathrm{O}_{3}$ & 12,50 & 12,28 & 12,29 & 12,23 \\
\hline $\mathrm{Fe}_{2}^{2} \mathrm{O}_{3}^{3}$ & 12,34 & 10,73 & 10,59 & 10,58 \\
\hline $\mathrm{CaO}^{2}$ & 0,10 & 0,09 & 0,08 & 0,09 \\
\hline $\mathrm{Na}_{2} \mathrm{O}$ & 0,07 & 0,05 & 0,08 & 0,04 \\
\hline $\mathrm{K}_{2} \mathrm{O}^{2}$ & $<0,01$ & $<0,01$ & $<0,01$ & $<0,01$ \\
\hline $\mathrm{MnO}$ & 0,15 & 0,14 & 0,14 & 0,14 \\
\hline $\mathrm{TiO}_{2}$ & 0,25 & 0,26 & 0,27 & 0,27 \\
\hline $\mathrm{MgO}^{2}$ & 0,10 & 0,10 & 0,09 & 0,09 \\
\hline $\mathrm{P}_{2} \mathrm{O}_{5}$ & 0,23 & 0,23 & 0,23 & 0,23 \\
\hline PFOGO & 9,84 & 12,27 & 12,33 & 12,15 \\
\hline Total & 92,51 & 93,33 & 93,22 & 93,03 \\
\hline $\mathrm{Si} / \mathrm{Al}$ & 4,55 & 4,65 & 4,65 & 4,67 \\
\hline
\end{tabular}

Difração de raios $X$

A Fig. 1 apresenta as curvas de difração obtidas para as amostras de argila bentonítica natural e ativada com ácido clorídrico a diferentes tempos de reação com a granulometria de 80 mesh.

Pode-se observar que a análise da argila bentonítica 

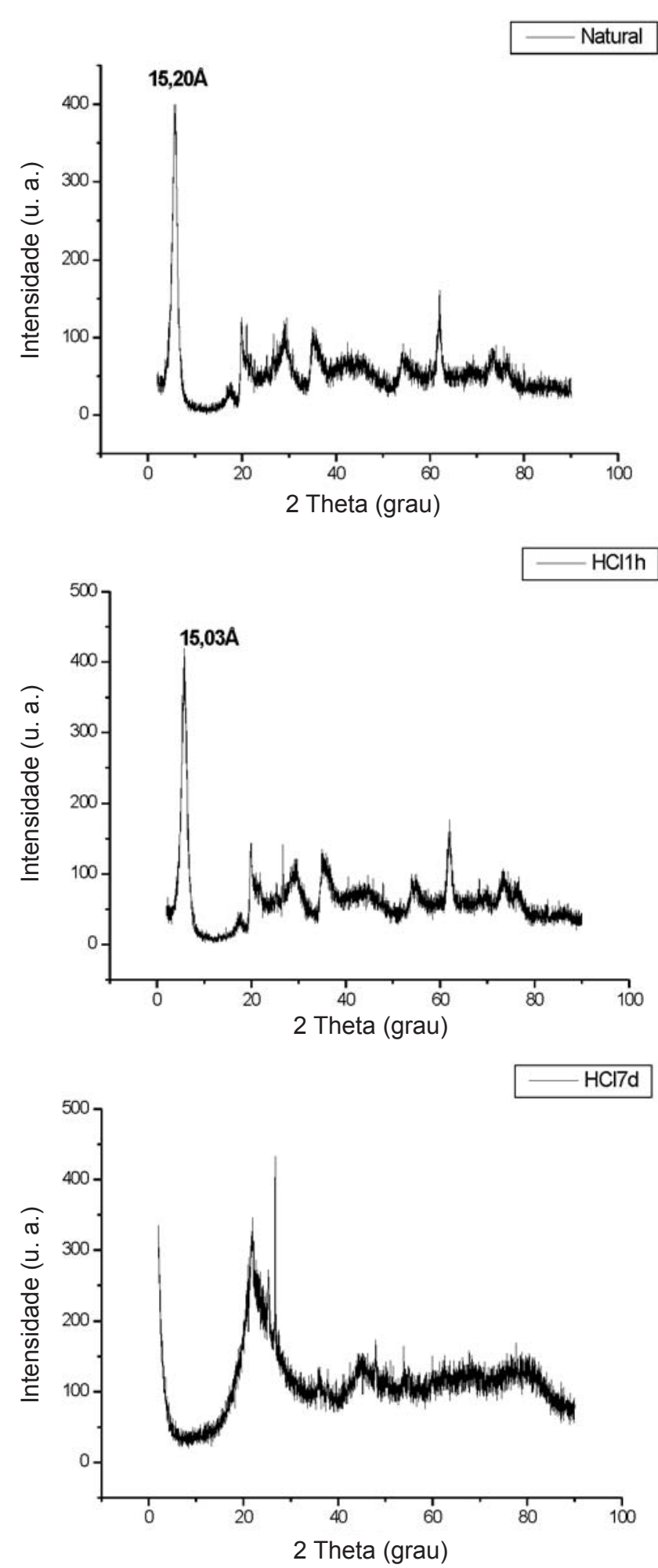

Figura 1: Difratogramas de raios $\mathrm{X}$ da argila bentonítica 80 mesh: sem tratamento e após ativação com $\mathrm{HCl}(6 \mathrm{M})$ por $1 \mathrm{~h}$ e $7 \mathrm{~d}$.

[Figure 1: X-ray diffraction patterns of the bentonites: natural untreated and activated with $\mathrm{HCl}(1 \mathrm{~h}$ and $7 \mathrm{~d})$.

(80 mesh) sem tratamento evidencia a presença de montmorilonita e quartzo na amostra. Analisando o difratograma da argila bentonítica ( 80 mesh) tratada com solução de ácido clorídrico (6M), pode-se dizer que do
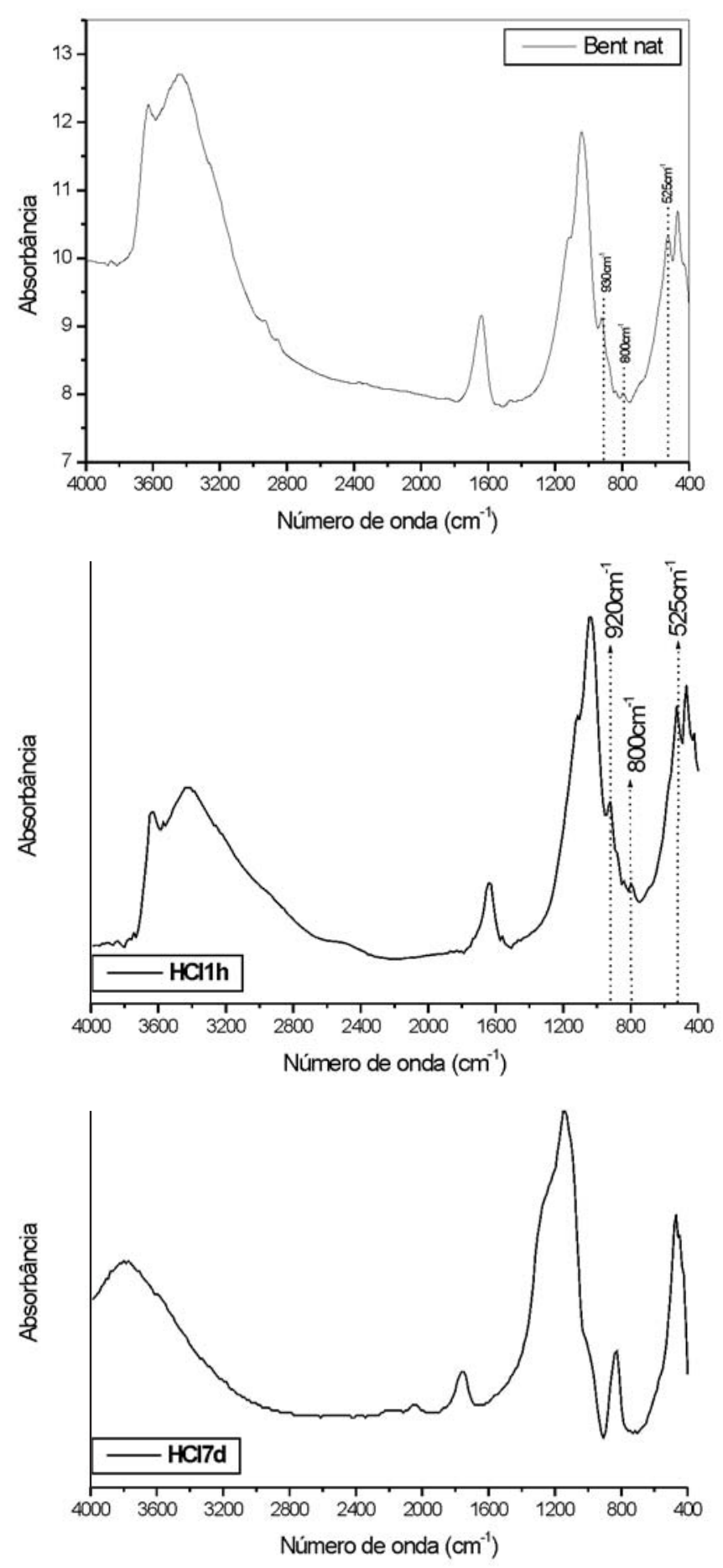

Figura 2: Espectros de infravermelho da argila bentonítica 80 mesh sem tratamento e após ativação com $\mathrm{HCl}(6 \mathrm{M})$ por $1 \mathrm{~h}$ e $7 \mathrm{~d}$.

[Figure 2: Infrared spectra of the bentonites: natural untreated and activated with $\mathrm{HCl}(1 \mathrm{~h}$ and $7 d)$.

ponto de vista estrutural, o material não sofreu alterações significativas, apenas diminuiu a intensidade do pico característico da montmorilonita $\left(\mathrm{d}_{001}=15,03 \AA\right)$, indicando uma possível distorção no arranjo dos íons constituintes das camadas octaédricas e tetraédricas, em virtude da provável troca iônica, já que o arranjo interlamelar é diretamente dependente do cátion. 


\section{Espectroscopia na região do infravermelho}

A Fig. 2 apresenta os espectros na região do infravermelho da amostra natural e após ativação com ácido clorídrico (6M) por $1 \mathrm{~h}$ e $7 \mathrm{~d}$.

Os picos característicos das camadas octaédricas são freqüentes nas faixas de $920 \mathrm{~cm}^{-1}, 800 \mathrm{~cm}^{-1}$ e $525 \mathrm{~cm}^{-1}$ [19] e o pico evidente em $3600 \mathrm{~cm}^{-1}$ é referente à absorção de água [20]. Verificam-se estes picos na amostra natural e na amostra ativada com o ácido clorídrico (6M) para o tempo de reação de $1 \mathrm{~h}$ (Fig. 2). Observa-se ainda que a amostra ativada para o tempo de reação de $7 \mathrm{~d}$ não apresenta os picos característicos das camadas octaédricas, sendo este tratamento severo, promovendo uma destruição acentuada das camadas do argilomineral esmectítico, estando em conformidade com os difratogramas de raios $\mathrm{X}$.

\section{Estudo do uso da argila tratada como catalisador ácido}

O meta-xileno foi selecionado como reagente para os testes de avaliação catalítica, tendo sua reação de isomerização sido utilizada para avaliar as atividades dos catalisadores. Na Tabela II estão apresentados os resultados das conversões do meta-xileno, com exceção da amostra tratada com tempo de reação de $7 \mathrm{~d}$, pois este evidenciou perda significativa da estrutura do material.

Tabela II - Isomerização do meta-xileno sobre diversos catalisadores a $350{ }^{\circ} \mathrm{C}$. Conversão (X) do meta-xileno (\%) para os diversos catalisadores.

[Table II - Isomerization of meta-xylene with catalysts at $350{ }^{\circ} \mathrm{C}$. Conversion of meta-xylene (\%) for catalysts].

\begin{tabular}{lc}
\hline Catalisador (Argila bentonítica 80 mesh) & X (\%) \\
\hline Sem tratamento & 6,98 \\
Ativada com $\mathrm{HCl}(6 \mathrm{M}) 1$ & 12,44 \\
Ativada com $\mathrm{HCl}(6 \mathrm{M}) 2 \mathrm{~h}$ & 13,58 \\
Ativada com $\mathrm{HCl}(6 \mathrm{M}) 3 \mathrm{~h}$ & 17,52 \\
\hline
\end{tabular}

Os testes de avaliação catalítica realizados durante a isomerização do meta-xileno mostraram que todos os catalisadores são ativos para a referida reação.

Ao analisar os resultados da Tabela II é possível verificar que as conversões do meta-xileno sobre catalisadores, argila bentonítica 80 mesh sem tratamento são inferiores à conversão do meta-xileno sobre as argilas ativadas $(1 \mathrm{~h}, 2 \mathrm{~h}$ e $3 \mathrm{~h}$ ). Este comportamento pode ser explicado pelo fato da ativação com ácido clorídrico diminuir o teor de ferro nas amostras, tornando os catalisadores mais eficientes.

\section{CONCLUSÕES}

De acordo com os resultados de difração de raios $\mathrm{X}$ e de absorção óptica na região do infravermelho, verificouse que para o tempo de reação de $1 \mathrm{~h}$, que é menor que os usualmente empregados pela indústria, a utilização do ácido clorídrico não causou modificações acentuadas na estrutura do argilomineral esmectítico.
Observou-se que para o tempo de reação de $7 \mathrm{~d}$, significativamente maior que os tempos de ataque empregados pela indústria, o ácido clorídrico causou danos significativos à estrutura, proporcionando um material basicamente amorfo com pequeno grau de cristalinidade.

Os testes de avaliação catalítica realizados durante a isomerização do meta-xileno mostraram que todos os catalisadores são ativos para a referida reação, porém a conversão melhora com o tratamento ácido ( 1 h, 2 h e 3 h).

\section{AGRADECIMENTOS}

Os autores agradecem, em especial, ao CNPq pela bolsa de mestrado.

\section{REFERÊNCIAS}

[1] A. Moronta, V. Ferrer, J. Quero, G. Arteaga, E. Choren, Appl. Catalysis A: General 230 (2002) 127.

[2] H. Kaplan, US Patent 32874224 (1966).

[3] F. Hojabri, Appl. Chem. Biotechnol. 21 (1971) 87.

[4] D. Nijopwouo, G. Roques, R. A. Wandji, Clay Miner. 22 (1987) 145 .

[5] D. A. Morgan, D. B. Shaw, M. J. Sidedbottom, T. O. Soon, R. S. Taylor, J. Am. Oil Soc. 62 (1985) 292.

[6] R. Fahn, K. Fenderl, Clay Miner. 16 (1981) 1.

[7] N. Bessün, F. Özkan, G. Gündüz, Appl. Catalysis A: General 224 (2002), 285.

[8] R. S. Chitnis, M. M. Sharma, Reactive \& Functional Polymers. 32 (1997) 93.

[9] U. Flessner, D. J. Jones, J. Roziére, J. Zajac, L. Storaro, M. Lenarda, M. Pavan, A. Jiménez-Lopez, E. RodriguezCastellón, M. Trombetta, G. Busca, J. Molecular Catalysis A: Chemical 168 (2001) 247.

[10] M. S. Barrios, L. V. F. González, M. A. V. Rodríguez, J. M. M. Pozas, Appl. Clay Sci. 10 (1995) 247.

[11] J. L. Bonilla, J. de D. Lopez Gonzalez, A. Ramírez Saen, J. Rodríguez Reinoso, C. Valenzuela Calahorro, Clay Miner. 16 (1981) 173.

[12] J. de D. López González, A. Ramírez Saen, F. Rodríguez Reinoso, C. Valenzuela Calahorro, L. Zurita Herrera, Clay Miner. 16 (1981) 103.

[13] H. Cetisli, T. Gedikbey, Clay Miner. 25 (1990) 207-215.

[14] C. Pesquera, F. Gonzalez, I. Benito, C. Blanco, S. Mendiorez, J. Pajares, J. Mater. Chem. 2, 9 (1992) 907.

[15] C. N. Rhodes, M. Franks, G. M. B. Parkes, D. R. Brown, J. Chem. Soc.-Chem. Comm. 12 (1991) 804.

[16] C. N. Rhodes, D. R. Brown, J. Chem. Soc. 88 (1992) 2269.

[17] P. Kumar, R. V. Jasra, T. S. G. Bhat, Ind. Eng. Chem. Res. 34 (1995) 1440.

[18] M. G. F. Rodrigues, Cerâmica. 49 (2003) 146.

[19] S. Mendioroz, J. A. Pajares, I. Benito, C. Pesquera, F. González, C. Blanco, Langmuir. 3 (1987) 676.

[20] R. M. Silverstein, G. C. Bassler, T. C. Morrill, Identificação espectrométrica de compostos orgânicos, Guanabara Koogan S. A., Rio de Janeiro, Brasil (1989) 299.

(Rec. 31/12/2005, Rev. 04/05/2006, Ac. 13/09/2006) 